\title{
GEOSUL
}

\section{ZONEAMENTO GEOAMBIENTAL DO MUNICÍPIO DE CACEQUI, RIO GRANDE DO SUL}

\author{
Lucas Krein Rademann ${ }^{1}$ \\ Romario Trentin ${ }^{2}$ \\ Luis Eduardo de Souza Robaina ${ }^{3}$
}

\begin{abstract}
Resumo: O município de Cacequi, localizado no Oeste do Rio Grande do Sul é caracterizado pela ocorrência de diversos problemas ambientais relacionados com o solo arenoso e rochas sedimentares da região. O trabalho tem como objetivo classificar o município em Unidades Geoambientais, destacando as potencialidades e suscetibilidades. Para a elaboração do Zoneamento Geoambiental foram sobrepostos os mapas de formas de relevo, litologia e uso do solo e discriminadas dez unidades distintas. Há um predomínio da Unidade Cacequi (36\%) que é caracterizada por solos pouco férteis e de grande ocorrência de processos erosivos lineares, fazendo-se necessário uma ocupação antrópica menos intensa nestas áreas. De modo geral, Cacequi está localizado em uma área de grande fragilidade ambiental, necessitando de um planejamento ambiental contínuo no município.
\end{abstract}

Palavras-chave: Geoambiental; Geoprocessamento; Cacequi; Oeste do Rio Grande do Sul

\section{GEOENVIRONMENTAL ZONING OF THE MUNICIPALITY OF CACEQUI, RIO GRANDE DO SUL}

\begin{abstract}
The municipality of Cacequi, located in the west of Rio Grande do Sul is characterized by the occurrence of several environmental problems related to the sandy soil and sedimentary rocks of the region. The objective of this work is to classify the municipality into Geoenvironmental Units, highlighting potentialities and susceptibilities. For the elaboration of the Geoenvironmental Zoning maps of relief forms, lithology and land use were overlaid and then ten distinct classes were discriminated. There is a predominance of the Cacequi Unit (36\%), which is characterized by low fertile soils and high occurrence of linear erosive processes, making less intense anthropic occupation necessary in these areas. In general, Cacequi is located in an area of great environmental fragility, requiring continuous environmental planning in the municipality.
\end{abstract}

Keywords: Geoenvironmental; Geoprocessing; Cacequi; West of Rio Grande do Sul

\section{ZONIFICACIÓN GEOAMBIENTAL DEL MUNICIPIO DE CACEQUI, RIO GRANDE DO SUL}

Resumen: El municipio de Cacequi, localizado en el Oeste de Rio Grande do Sul, se caracteriza por la ocurrencia de diversos problemas ambientales relacionados con el suelo arenoso y rocas sedimentarias de la región. El trabajo tiene como objetivo clasificar el municipio en Unidades Geoambientales, destacando las potencialidades y susceptibilidades. Para la elaboración de la Zonificación Geoambiental se superponen los mapas de formas de relieve, litología y uso del suelo y discriminadas diez unidades distintas. Hay un predominio

\footnotetext{
${ }^{1}$ Graduando em Geografia. Universidade Federal de Santa Maria. Email: lucasrademann@yahoo.com

${ }^{2}$ Professor Doutor do Departamento de Geociências da Universidade Federal de Santa Maria. Email: romario.trentin@gmail.com

${ }^{3}$ Professor Doutor do Departamento de Geociências da Universidade Federal de Santa Maria. Email: lesrobaina@yahoo.com.br
} 
de la Unidad Cacequi (36\%) que se caracteriza por suelos poco fértiles y de gran ocurrencia de procesos erosivos lineales, haciendo necesaria una ocupación antrópica menos intensa en estas áreas. En general, Cacequi está ubicado en un área de gran fragilidad ambiental, necesitando de una planificación ambiental continua en el municipio.

Palabras clave: Geoambiental; Geoprocesamiento; Cacequi; Oeste de Rio Grande do Sul

\section{INTRODUÇÃO}

O termo "Geoambiental" vem a atender uma tendência na atuação de profissionais ligados principalmente aos estudos do meio ambiente desenvolvidos pelas Geociências, onde conhecimentos técnicos sobre o meio físico dispõem a respeito do planejamento e gestão ambiental. A incorporação deste termo aos estudos se dá na tentativa de não estreitar os campos de atuação de determinados profissionais, além de favorecer estudos integrados de especialistas da área principalmente quando seus resultados se apresentam através da cartografia (VEDOVELLO, 2004).

O resultado do mapeamento pode ser considerado uma técnica de integração e síntese de informações temáticas voltadas para o planejamento ambiental permitindo assim a formulação de modelos. Esses modelos podem indicar o comportamento de determinadas áreas, bem como permitir que a soluções destes problemas, desenvolvidos por fatores físicos ou antrópicos, possam ser discutidos e implantados (DINIZ, 2012).

Portanto, os estudos geoambientais permitem estabelecer relações entre as condições naturais e a apropriação do espaço através da ação antrópica, permitindo indicar suscetibilidades e potencialidades.

Assim destacam Freitas Filho e Souza (2005) que a análise geoambiental, através da abordagem multi-interdisciplinar, passou a ser tema de estudo de um grande número de pesquisadores.

Quanto a importância dos estudos geoambientais destacam Robaina et al (2009) que

Nos últimos anos, vêm ganhando força às discussões a respeito dos zoneamentos geoambientais, principalmente, pela importância que vem tendo como instrumento estratégico para o planejamento regional, com forte vinculação ao parcelamento do solo e definições de usos.

Ohara et al (2003) salienta que o estudo geoambiental deve ter como meta, o fornecimento de subsídios técnicos para orientar e elucidar a tomada de decisões na implementação de alternativas de desenvolvimento regional compatíveis com a sustentabilidade e vulnerabilidade dos sistemas ambientais. 
A área de estudo é o município de Cacequi onde ocorrem diversos problemas ambientais relacionados com o solo arenoso e rochas sedimentares da região, causando problemas de voçorocamento, perda de solo, ravinamento e assoreamento dos rios. Este trabalho tem como objetivo, através de mapeamentos temáticos, classificar o município em Unidades Geoambientais, destacando as potencialidades e suscetibilidades. Trentin (2011) chama a atenção à necessidade de planejamento destas áreas marcadas por grande susceptibilidade à dinâmica superficial, como as registradas no oeste do Rio Grande do Sul.

O município de Cacequi está localizado na porção Oeste do estado do Rio Grande do Sul, entre as coordenadas geográficas $-29^{\circ} 43^{\prime} 28^{\prime \prime}$ a $-30^{\circ} 8^{\prime} 31^{\prime \prime}$ no sentido Norte-Sul e das coordenadas $-54^{\circ} 15^{\prime}, 52^{\prime}$ ' a $-55^{\circ} 18^{\prime} 13^{\prime \prime}$, no sentido Leste-Oeste. Os municípios que fazem limite com Cacequi são: São Vicente do Sul e São Pedro do Sul a Norte, Dilermando de Aguiar a Leste, Alegrete a Oeste e Rosário do Sul e São Gabriel ao Sul (Figura 1). 


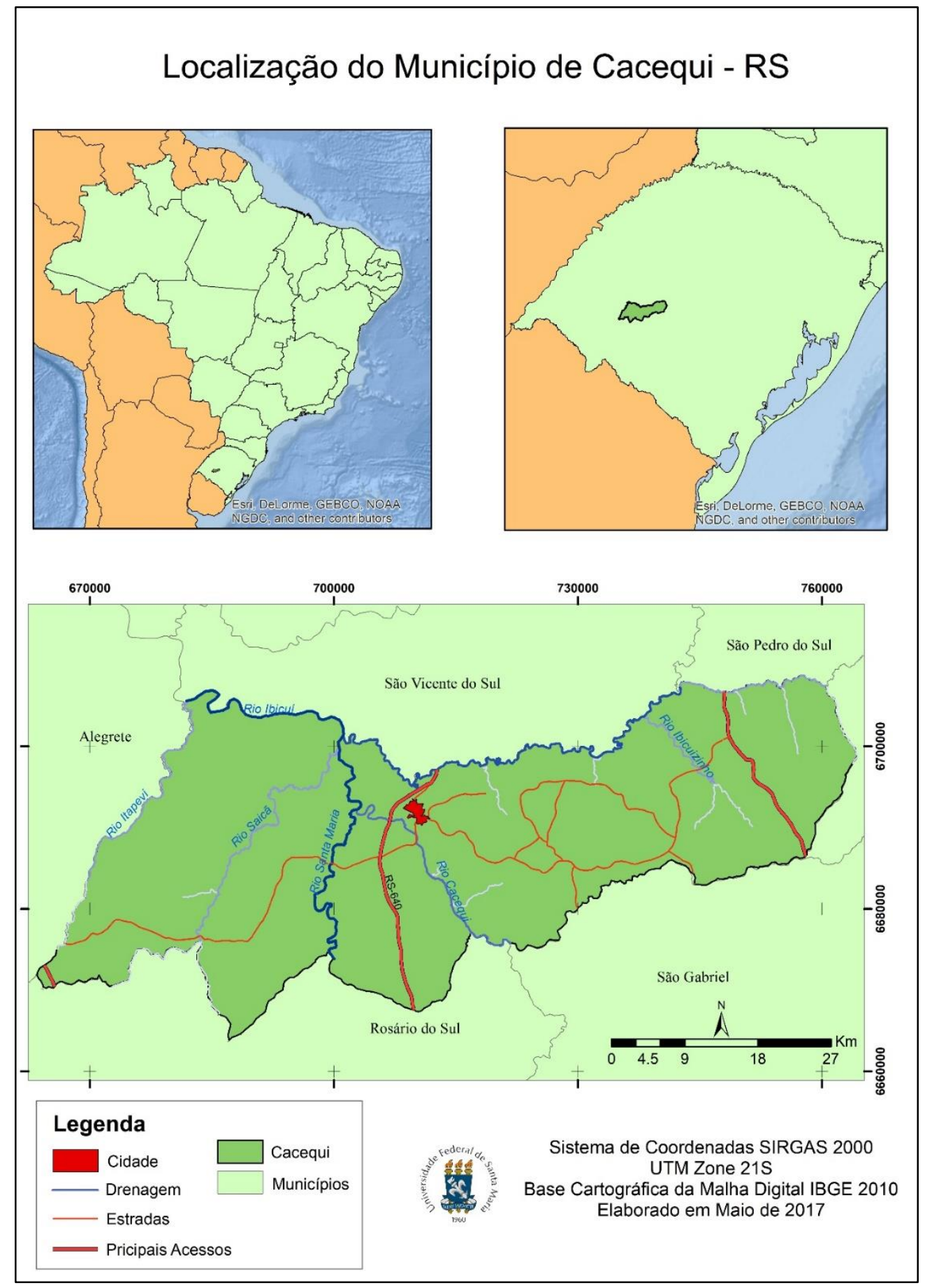

Figura 1 - Mapa de Localização do Município de Cacequi, RS.

\section{METODOLOGIA}

Na elaboração dos mapas foi utilizado a malha digital do IBGE para o limite do município e as Cartas Topográficas 1:50.000 do Exército Brasileiro para o mapeamento da rede de drenagem, com a vetorização dos segmentos de canais fluviais, que foram ordenados de acordo com sua hierarquia segundo o método de Strahler (1952). Após a hierarquização da 
drenagem de Cacequi, o município foi subdividido em sub-bacias hidrográficas de ordem maior ou igual a quatro, para melhor analisar a hidrografia da área.

Com o uso da ferramenta spatial analyst do ArcGis 10.1 foram gerados dados de cada bacia hidrográfica do município permitindo então o cálculo do índice de Densidade de Drenagem. Os cálculos referentes à morfometria das bacias foram feitos com o auxílio da planilha do Excel 2010, onde também foram geradas as tabelas e produzidos os gráficos presentes neste trabalho.

Para os cálculos de Densidade de Drenagem que é a relação entre o comprimento dos canais e a área da bacia, estabelecido por Horton (1945 apud Christofoletti 1974), foi utilizada a expressão Dd=Lt/A; em que Dd corresponde Densidade de Drenagem; Lt refere-se ao comprimento total dos segmentos fluviais e A é a área total da bacia.

Para a elaboração do mapa hipsométrico de Cacequi foram digitalizadas as curvas de nível e pontos cotados das Cartas Topográficas do Exército Brasileiro de 1:50.000, posteriormente utilizada a ferramenta Topo to Raster do SIG ArcGIS 10.1. Estabeleceu-se então cinco classes para altitude do município de acordo com a variação média do relevo, sendo estas menores de 80 metros, de 80 até 110 metros, altitudes entre 110 e 140 metros, de 140 a 170 metros e também altitudes superiores a 170 metros.

$\mathrm{Na}$ elaboração do mapa de declividade, que foi realizado com o mesmo banco de dados do mapa hipsométrico, foi utilizada a ferramenta Slope e gerado o mapa de declividade. Foram estabelecidos os seguintes limites de classe de acordo com a metodologia proposta pelo IPT (1981) e apresentado por Trentin e Robaina (2006): 2\%, 5\% e 15\% em que as áreas com declividade de $2 \%$ são muito planas e presente o processo de deposição, áreas de declividade de $5 \%$ são áreas de transição entre processos de deposição e meteorização, e as declividades de $15 \%$ representam áreas propícias para movimento de massas e limite para uso de maquinário agrícola. Sendo assim, as declividades de Cacequi foram divididas em quatro classes, sendo estas as menores que $2 \%$, entre 2 e $5 \%$, valores de 5 a $15 \%$ e superiores a $15 \%$.

Para determinação das formas de relevo foram relacionadas as variáveis hipsometria, declividade e a amplitude das encostas através de perfis topográficos.

A análise da litologia se deu através de análise dos dados da CPRM (2006) que foram detalhados através de trabalhos de campo com a elaboração de perfis de caminhamentos, com coletas de amostras de rochas ao longo da área do município, percorrendo as estradas e caminhos e após processados os dados foi elaborado o mapa litológico no ArcGis 10.1. 
Para a elaboração do estudo das unidades morfolitológicas em Cacequi foram utilizados os mapas de formas de relevo e litológico, que sobrepostos foram discriminadas nove áreas homogêneas que são as unidades morfolitológicas do município.

As imagens de satélite utilizadas para a elaboração do mapa de uso do solo são do sensor OLI do LANDSAT 8. As imagens foram escolhidas de acordo com a cobertura de nuvens do local e são datadas de 04/12/2014. A orbita do satélite que cobre o município é a 223 e o ponto é 81 , sendo que as imagens foram retiradas do site earthexplorer.usgs.gov.

No software ENVI Classic foram coletadas amostras conhecidas de cada classe e foram classificadas de forma supervisionada (Maxver) no mesmo software de acordo com a sua reflectância igual ou semelhante individualizando os pixels da imagem. Após foram classificadas e unidas as formas iguais em polígonos gerando assim uma base de dados para a elaboração de mapas no SIG ArcGIS 10.1.

Para a elaboração do mapa geoambiental foram analisadas as variáveis ambientais do município e o uso e ocupação do solo que foram cruzados e resultaram em dez unidades geoambientais. Após a definição e delimitação das unidades geoambientais, foram apontadas suscetibilidades e potencialidades das mesmas de acordo com as condições de cada unidade.

Após a elaboração dos mapas foram feitas análises quantitativas e qualitativas das variáveis ambientais, como também do uso e ocupação do solo.

\section{RESULTADOS}

Cacequi é drenado principalmente pelos rios Ibicuí, que faz o seu limite Norte, rio Santa Maria, presente na porção Centro-Oeste do município, rio Cacequi na porção Central e outros rios de menor ordem como Pau-Fincado no seu limite Leste, Ibicuízinho na porção Leste, e Itapevi e Saicã na porção Oeste. Sendo assim, a hidrografia de Cacequi é dividida em 10 Sub-Bacias, conforme representado pelo mapa da Figura 2. 


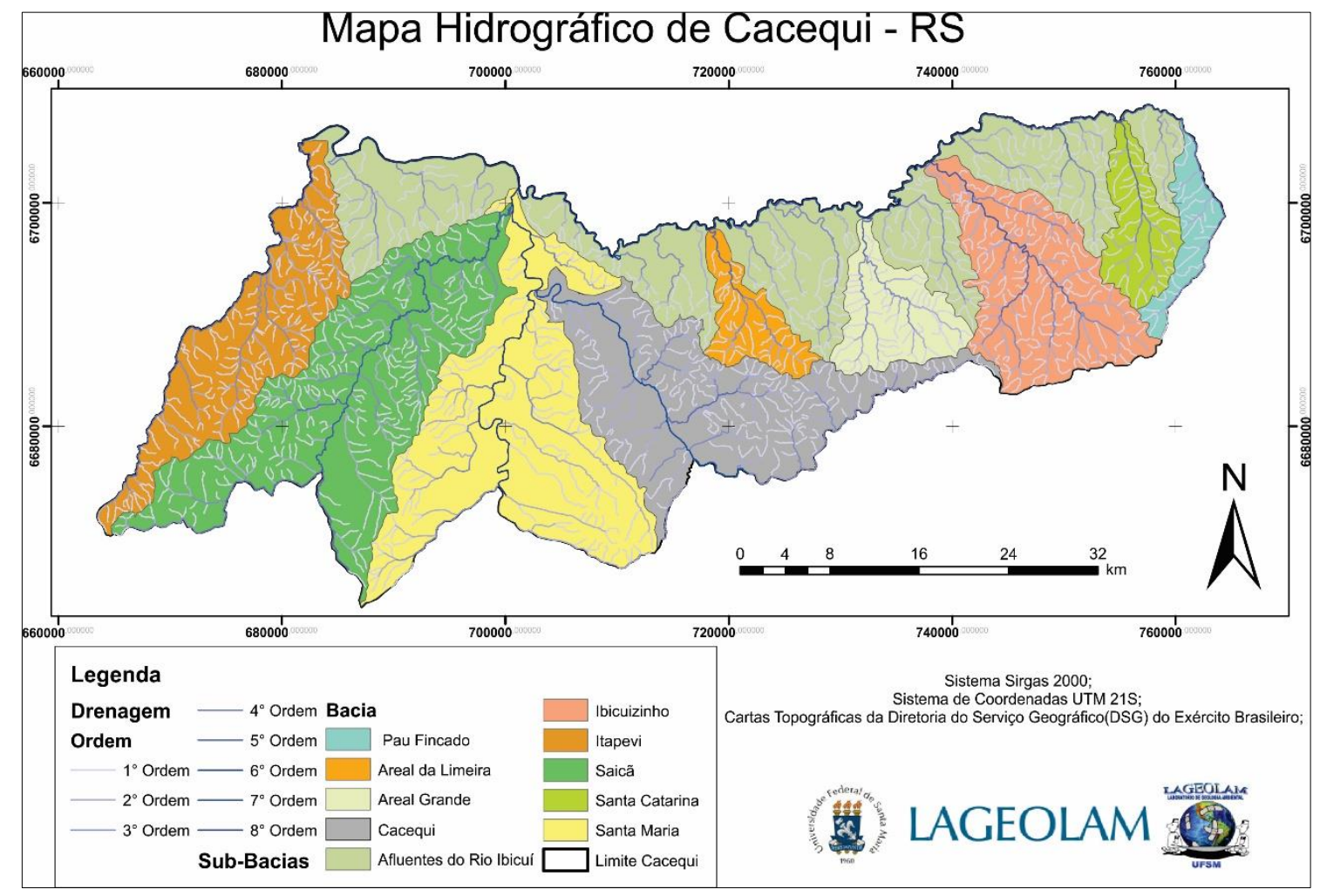

Figura 2 - Bacias Hidrográficas do Município de Cacequi - RS.

A drenagem de Cacequi possui um total de 1.554 segmentos de canais com $3.072,02 \mathrm{~km}$ de comprimento, dividida em 1.161 segmentos de canais de $1^{\circ}$ ordem com $1.677,09 \mathrm{~km}$ de comprimento, 293 segmentos de canais de $2^{\circ}$ ordem com $605,73 \mathrm{~km}$ de comprimento, 79 segmentos de canais de $3^{\circ}$ ordem com $383,34 \mathrm{~km}$ de comprimento, 13 segmentos de canais de $4^{\circ}$ ordem com $107,75 \mathrm{~km}$ de comprimento, 4 segmentos de canais de $5^{\circ}$ ordem com $120,17 \mathrm{~km}$ de comprimento, 1 segmento de canal de $6^{\circ}$ ordem com $34,45 \mathrm{~km}$ de comprimento, 1 segmento de canal de $7^{\circ}$ ordem com $74,11 \mathrm{~km}$ de comprimento, e 2 segmentos de canais de $8^{\circ}$ ordem com $70,61 \mathrm{~km}$ de comprimento. Rede hidrográfica, a qual possui um padrão de drenagem paralelo-dendrítica em quase toda a sua extensão, característica de regiões sedimentares, em que os cursos de água possuem um padrão que se assemelha à configuração de uma árvore, onde os canais tributários distribuem-se em todas as direções formando ramos chegando ao canal principal que se assemelha a um tronco.

Quanto aos parâmetros das bacias hidrográficas de Cacequi podemos salientar a densidade de drenagem, que na maioria das sub-bacias é inferior a 1,5 excetuando as subbacias do Itapeví e Pau-Fincado (Tabela 1). 
RADEMANN, L. K.; TRENTIN, R; ROBAINA, L.E.S.

Tabela 1 - Análise da Drenagem de Cacequi - RS.

\begin{tabular}{|c|c|c|c|c|}
\hline Nome da Bacia & Área(km $\left.{ }^{2}\right)$ & Comprimento total dos rios $(\mathbf{k m})$ & Ordem & Densidade de drenagem $\mathbf{k m} / \mathbf{k m}^{\mathbf{2}}$ \\
\hline Areal Grande & 94,09 & 124,07 & 4 & 1,31 \\
\hline Areal do Limeira & 60,7 & 86,8 & 4 & 1,43 \\
\hline Cacequi & 325,36 & 384,22 & 6 & 1,18 \\
\hline Ibicuí & 513,77 & 675,35 & 8 & 1,31 \\
\hline Ibicuízinho & 218,2 & 322,1 & 5 & 1,47 \\
\hline Itapeví & 224,89 & 357,22 & 5 & 1,58 \\
\hline Pau-Fincado & 43,86 & 72,17 & 4 & 1,64 \\
\hline Saicã & 402,25 & 523,89 & 5 & 1,3 \\
\hline Santa Catarina & 72,17 & 97,92 & 4 & 1,35 \\
\hline Santa Maria & 383,19 & 381,63 & 8 & 0,99 \\
\hline
\end{tabular}

De modo geral, o município possui uma Densidade de Drenagem de $1,35 \mathrm{~km} / \mathrm{km}^{2}$ que é considerada baixa segundo Villela e Mattos (1975) que considerava que se for maior que 3,5 $\mathrm{km} / \mathrm{km}^{2}$ é excepcionalmente bem drenada, e se for inferior a $0,5 \mathrm{~km} / \mathrm{km}^{2}$ é uma área de drenagem pobre. Deste modo a Densidade de Drenagem de Cacequi é baixa, o que representa a alta capacidade de absorção de água pelo solo e substrato que compõem o município.

Os dados de litologia e formas de relevo, permitiram definir nove unidades de relevo no município de Cacequi que estão espacializadas no mapa da Figura 3.

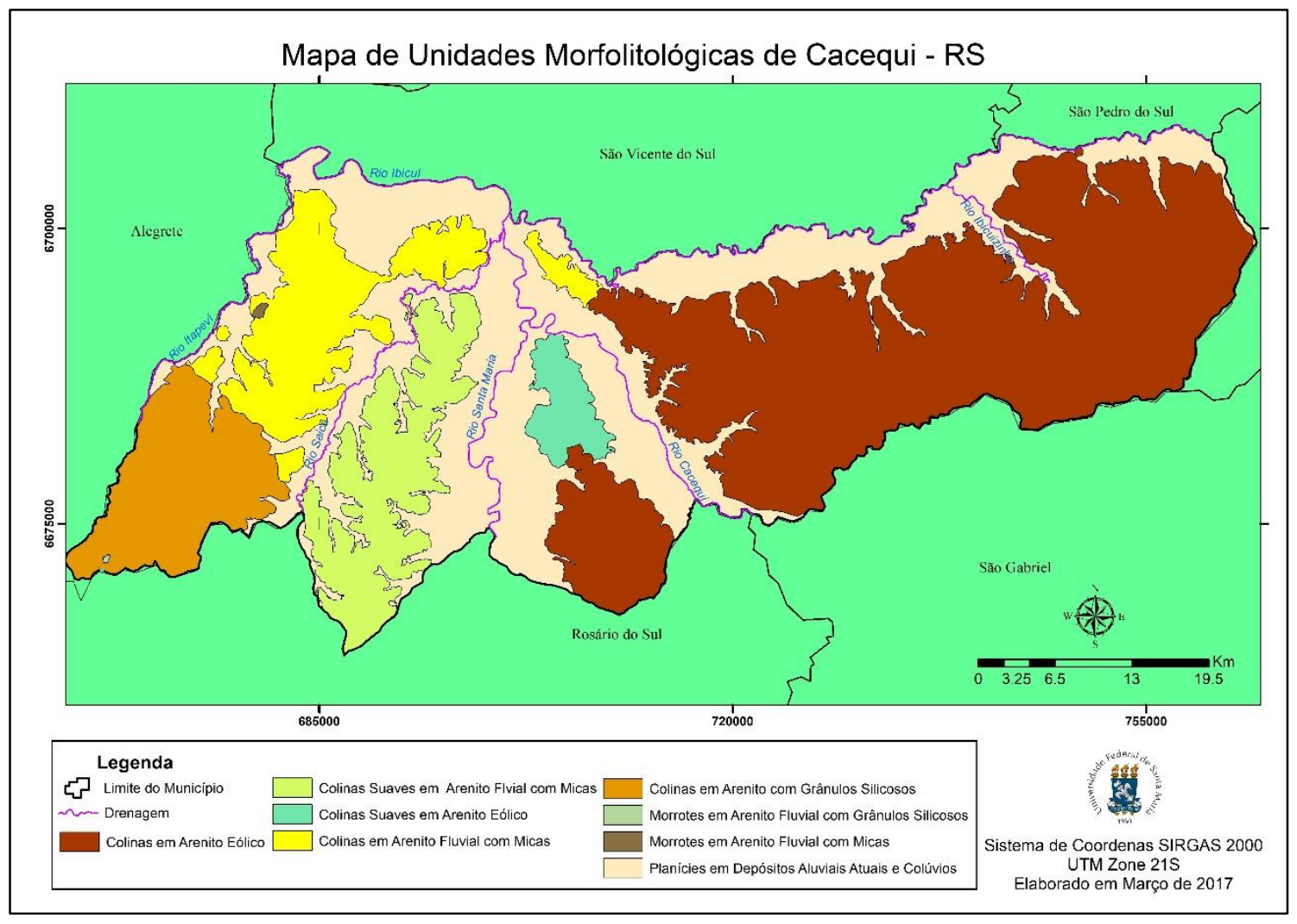

Figura 3 - Compartimentação Morfolitológica de Cacequi - RS. 
O relevo de Colinas Suaves foi dividido em duas unidades definidas pelo tipo de substrato em Colinas Suaves em Arenito Eólico e Colinas Suaves em Arenito com Mica, que correspondem, respectivamente, a 1,99 e 8,21\% do território de Cacequi. As Colinas Suaves em Arenito Eólico estão presentes na porção Central no interflúvio dos rios Cacequi e Santa Maria. As Colinas Suaves em Arenito com Mica, localizam-se na porção entre os rios Santa Maria e Saicã. A unidade de arenitos eólicos forma solos friáveis e arenosos e são suscetíveis a erosão. A unidade de arenitos micáceos se caracterizam pela presença de ligantes de argila e óxidos de ferro. Formam solos não muito espesso, mas em geral com horizontes definidos.

As áreas definidas como de Colinas foram divididas em três unidades distintas, com base no substrato. As Colinas em Arenito Eólico, Colinas em Arenito Fluvial com Grânulos Silicosos e Colinas em Arenito Fluvial com Mica. Com relação as unidades anteriores são mais suscetíveis a processos erosivos devido a maior inclinação das encostas.

A unidade de Colinas em Arenito Eólico é a que têm maior expressão no município de Cacequi, estando presente em 39,21\% do município, principalmente na área Leste. Caracteriza-se por uma unidade de litologias friáveis e com declividades significativas, predominantes de 5 a $15 \%$. Podem ocorrer processos erosivos acelerados marcados por sulcos e voçorocas.

A Unidade de Colinas em Arenitos com Mica, representam uma área de 8,85\% do município. As litologias são friáveis e podem se desenvolver processos de sulcos significativos, marcando a suscetibilidade erosiva.

A Unidade de Colinas em Arenito com Grânulos Silicosos possui uma litologia um pouco mais resistente à erosão, devido ao ligante de sílica na rocha, tornando os processos erosivos mais moderados, está localizada na porção Sudoeste do município e representa $7,61 \%$ da área.

As áreas de morrotes foram subdividas em duas unidades morfolitológicas que são Morrote em Arenito Fluvial com Grânulos Silicosos e Morrote em Arenito Eólico, que correspondem respectivamente a 0,01 e 0,05\% da área. São áreas onde a litologia mais resistente formou, através da erosão diferencial, feições de elevações isolados no relevo, estando situados na porção Noroeste (Morrote em Arenito Eólico) e na porção Sudoeste (Morrote em Arenito Fluvial com Grânulos Silicosos).

A unidade de Planícies em Depósitos Aluviais Atuais, é caracterizada por baixas altitudes e declividades baixas, atuando sobre estes locais o processo de deposição. Esta unidade está presente nas planícies dos rios de maior expressão de Cacequi e representam 34,04\% da área do município. 
Quanto ao uso do solo, a maior porção do território de Cacequi é recoberta por lavouras, aproximadamente $44 \%$, estando espalhadas por todo o município, mas presentes em grande maioria nas regiões baixas, perto dos maiores rios do município, destacando-se as margens dos rios Ibicuí, Santa Maria e Cacequi (Figura 4). Estas lavouras, segundo dados do Censo Agropecuário do IBGE 2006, são utilizadas principalmente para a produção de Soja, Arroz, Milho e Trigo.

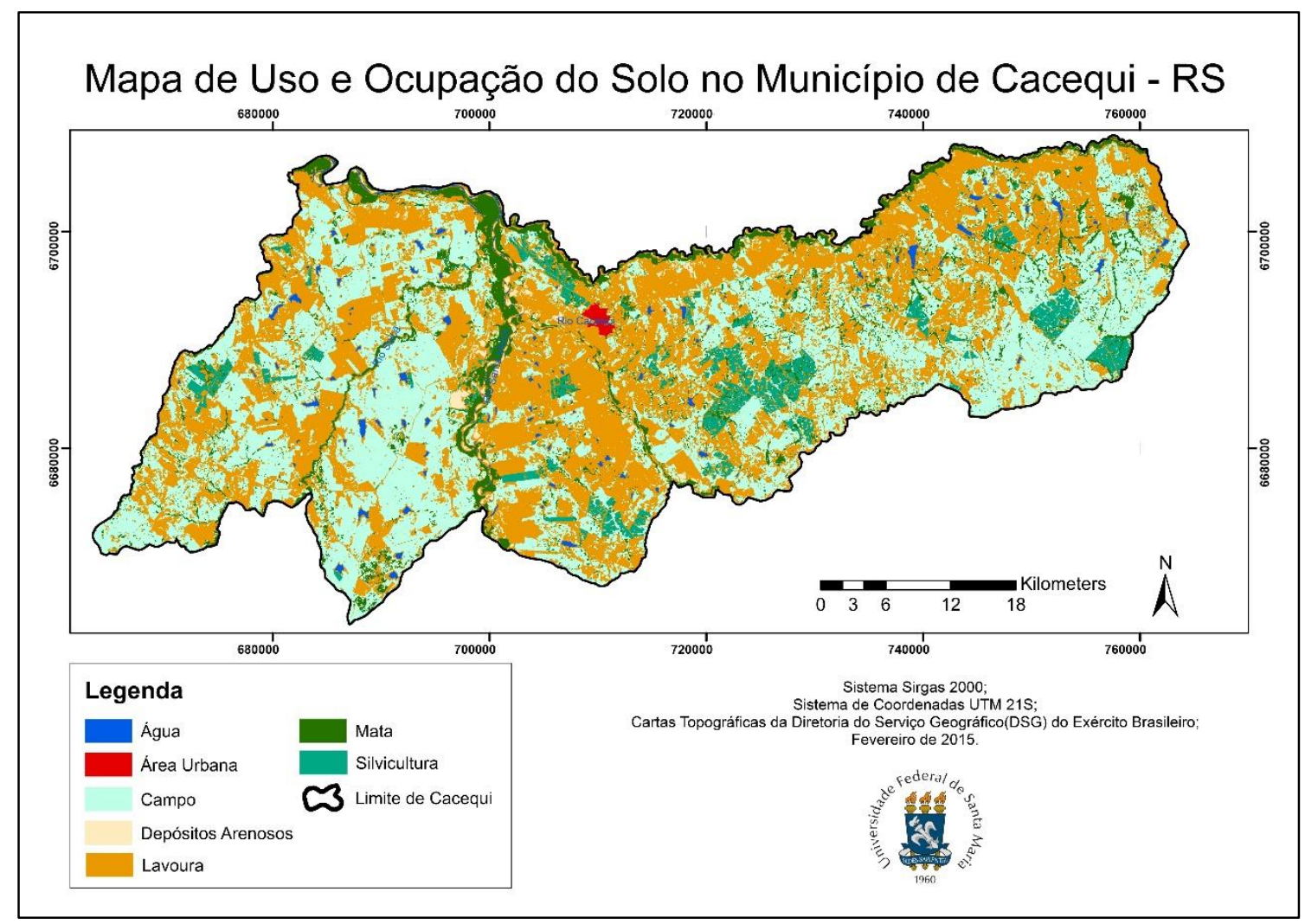

Figura 4 - Uso e Ocupação do Solo em Cacequi - RS.

A segunda maior porção de terras da área de estudo é recoberta por campos, presentes em $41 \%$ do território. São áreas onde há uma vegetação rasteira, com arbustos e alguns capões de mata nas áreas mais úmidas, o que caracteriza o bioma pampa. Os locais de campo nesta região do estado são comumente utilizados para a pecuária, tanto bovina como de ovinos.

Em 9\% do município de Cacequi há matas, que são matas de capões e matas ciliares. A grande maioria está localizada próxima aos rios de grande porte, sendo estes o Santa Maria, Cacequi e Ibicuí, porém as matas ciliares estão sendo suprimidas pela ação antrópica intensa, principalmente pela produção de arroz que utiliza as águas dos rios e se concentram em suas margens, consequentemente tomando áreas de matas ciliares.

A silvicultura é uma atividade que vem crescendo nas últimas décadas no Oeste do estado do Rio Grande do Sul e no município de Cacequi não tem sido diferente, hoje a 
silvicultura ocupa em torno de 101,53 $\mathrm{km}^{2}$ do território municipal (4\%), com o principal objetivo de extração de celulose, estando bastante concentrada nas colinas do município, principalmente no alto curso da sub-bacia do Rio Cacequi, a Noroeste da sede do município e na sub-bacia do Rio Ibicuízinho.

Também há em cerca de $1 \%$ da área de Cacequi os depósitos arenosos, que são depósitos associados às drenagens, localizados principalmente em áreas de planícies, pois são áreas de depósitos dos rios, e antigos meandros. São áreas de solos bastante inférteis, que dificultam o uso antrópico nestas áreas. Em Cacequi localizam-se nos bancos de deposição dos rios, nas áreas planas e baixas do município, principalmente próximo dos rios Cacequi, Santa Maria e Ibicuí.

Presente em 24,3 $\mathrm{km}^{2}$ (1\%) da área do município os corpos da água, caracterizam-se por reservatórios de água, utilizados para a irrigação de lavouras e dessedentação animal, no caso das áreas de campo e pecuária, e ainda algumas porções de cursos fluviais de grande porte, como o Rio Santa Maria e o Ibicuí.

A sede do município possui $4,52 \mathrm{~km}^{2}$, representando $0,2 \%$ da área total e está localizada a Norte do Rio Cacequi, caracterizada pela área mais urbanizada de Cacequi, possuindo maior acesso a serviços e infraestrutura.

Portanto, através da análise dos elementos físicos e as formas de uso e ocupação do solo do município e da agregação de áreas com características semelhantes foram definidas dez áreas com características diferentes, chamadas unidades geoambientais que estão representadas no mapa da Figura 5 e na Tabela da Tabela 2. 
RADEMANN, L. K.; TRENTIN, R; ROBAINA, L.E.S.

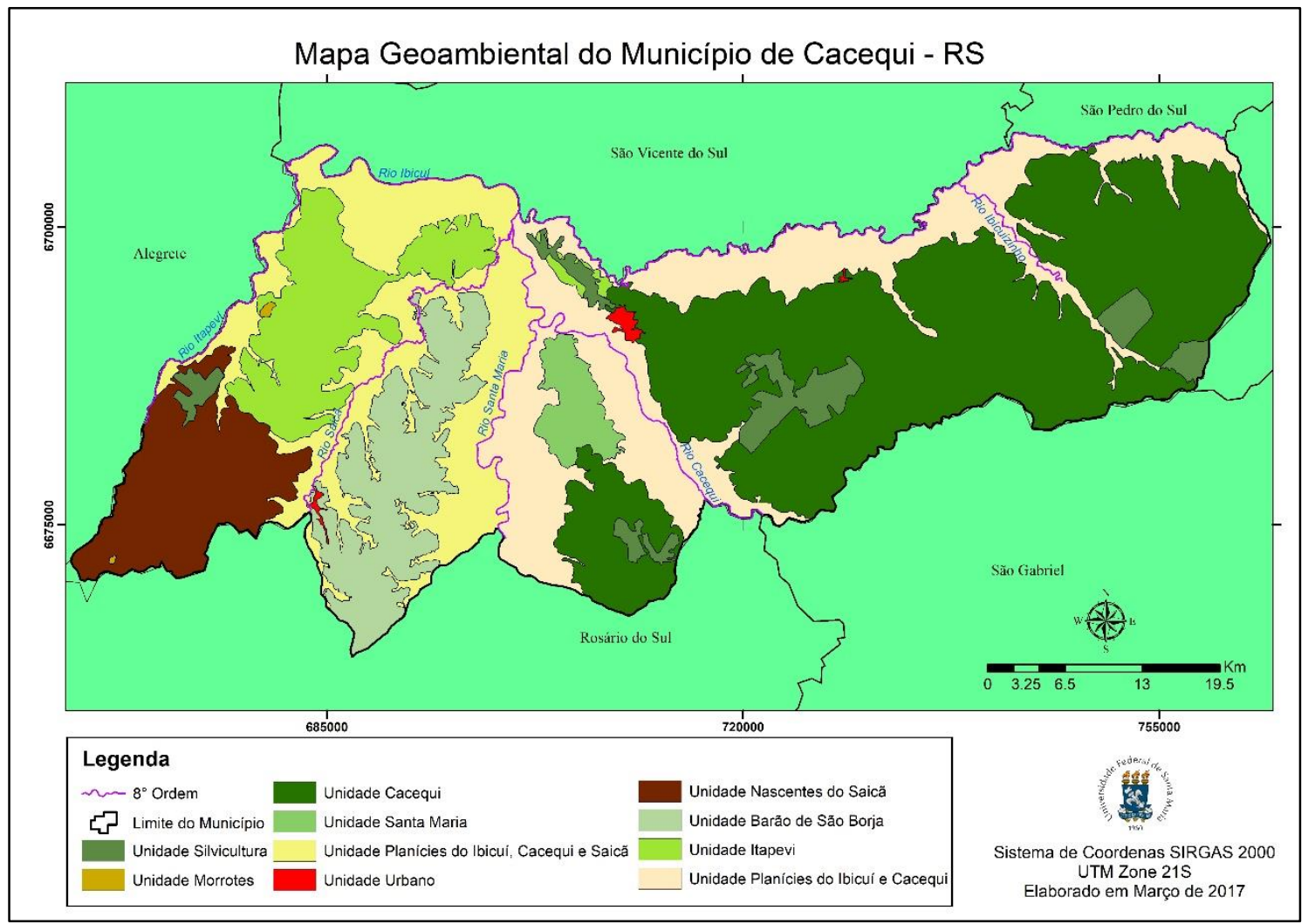

Figura 5 - Mapa das Unidades Geoambientais do Município de Cacequi - RS. 
RADEMANN, L. K.; TRENTIN, R; ROBAINA, L.E.S.

Tabela 2 - Unidades Geoambientais de Cacequi - RS.

\begin{tabular}{|c|c|c|c|c|}
\hline & Área Total $\left(\mathrm{km}^{2}\right)$ & Uso do Solo & Solo & $\begin{array}{l}\text { Unidade } \\
\text { Morfolitológica }\end{array}$ \\
\hline $\begin{array}{l}\text { Unidade } \\
\text { Urbano }\end{array}$ & 6.33 & Urbano & $\begin{array}{c}\text { Argissolo } \\
\text { Vermelho } \\
\text { Alumínico e } \\
\text { Argissolo } \\
\text { Vermelho Alítico }\end{array}$ & $\begin{array}{l}\text { Planícies em } \\
\text { Depósitos } \\
\text { Aluviais Atuais e } \\
\text { Colinas em } \\
\text { Arenito Eólico }\end{array}$ \\
\hline $\begin{array}{l}\text { Unidade } \\
\text { Silvicultura }\end{array}$ & 90.04 & Silvicultura & $\begin{array}{l}\text { Maior Parte em } \\
\text { Argissolo } \\
\text { Alumínico }\end{array}$ & $\begin{array}{l}\text { Predominância } \\
\text { de Colinas em } \\
\text { Arenito Eólico }\end{array}$ \\
\hline $\begin{array}{c}\text { Unidade } \\
\text { Planície do } \\
\text { Ibicuí e Cacequi }\end{array}$ & 439.51 & $\begin{array}{l}\text { Predomínio de } \\
\text { Lavouras }\end{array}$ & $\begin{array}{l}\text { Predomínio de } \\
\text { Planossolo } \\
\text { Háplico Eutrófico }\end{array}$ & $\begin{array}{l}\text { Planíceis em } \\
\text { Depósitos } \\
\text { Aluviais Atuais }\end{array}$ \\
\hline $\begin{array}{c}\text { Unidade } \\
\text { Planície do } \\
\text { lbicuí, Santa } \\
\text { Maria e Saicã }\end{array}$ & 340.07 & $\begin{array}{c}\text { Predomínio de } \\
\text { Campos, e } \\
\text { significativa } \\
\text { presença de Mata } \\
\text { Ciliar }\end{array}$ & $\begin{array}{l}\text { Predomínio de } \\
\text { Planossolo } \\
\text { Háplico Eutrófico }\end{array}$ & $\begin{array}{l}\text { Planíceis em } \\
\text { Depósitos } \\
\text { Aluviais Atuais }\end{array}$ \\
\hline $\begin{array}{l}\text { Unidade } \\
\text { Cacequi }\end{array}$ & 840.45 & $\begin{array}{l}\text { Campos e } \\
\text { Lavouras }\end{array}$ & $\begin{array}{l}\text { Argissolo } \\
\text { Vermelho } \\
\text { Alumínico }\end{array}$ & $\begin{array}{l}\text { Colinas em } \\
\text { Arenito Eólico }\end{array}$ \\
\hline $\begin{array}{c}\text { Unidade } \\
\text { Nascentes do } \\
\text { Saicã }\end{array}$ & 181.4 & $\begin{array}{l}\text { Predomínio de } \\
\text { Campos }\end{array}$ & $\begin{array}{l}\text { Predomínio de } \\
\text { Argissolo } \\
\text { Vermelho Alítico }\end{array}$ & $\begin{array}{l}\text { Colinas em } \\
\text { Arenito Fluvial } \\
\text { com Grânulos } \\
\text { Silicosos }\end{array}$ \\
\hline $\begin{array}{c}\text { Unidade Santa } \\
\text { Maria }\end{array}$ & 47.02 & Lavouras & $\begin{array}{l}\text { Argissolo } \\
\text { Vermelho } \\
\text { Alumínico }\end{array}$ & $\begin{array}{l}\text { Colinas Suaves } \\
\text { em Arenito Eólico }\end{array}$ \\
\hline Unidade Itapeví & 189.81 & $\begin{array}{l}\text { Predomínio de } \\
\text { Campos }\end{array}$ & $\begin{array}{l}\text { Predomínio de } \\
\text { Argissolo Bruno- } \\
\text { Acinzentado } \\
\text { Alítico }\end{array}$ & $\begin{array}{l}\text { Colinas em } \\
\text { Arenito Fluvial } \\
\text { com Mica }\end{array}$ \\
\hline $\begin{array}{l}\text { Unidade Barão } \\
\text { de São Borja }\end{array}$ & 192.06 & $\begin{array}{l}\text { Predomínio de } \\
\text { Campos }\end{array}$ & $\begin{array}{l}\text { Luvissolo } \\
\text { Háplico Órtico }\end{array}$ & $\begin{array}{c}\text { Colinas Suaves } \\
\text { em Arenito Fluvial } \\
\text { com Mica }\end{array}$ \\
\hline $\begin{array}{l}\text { Unidade } \\
\text { Morrotes }\end{array}$ & 1.37 & $\begin{array}{l}\text { Predomínio de } \\
\text { Campos }\end{array}$ & $\begin{array}{c}\text { Argissolo } \\
\text { Vermelho Alítico } \\
\text { e Argissolo } \\
\text { Bruno- } \\
\text { Acinzentado } \\
\text { Alítico } \\
\end{array}$ & $\begin{array}{l}\text { Morrote em } \\
\text { Arenito Fluvial } \\
\text { com Grânulos } \\
\text { Silicosos e } \\
\text { Arenito Fluvial } \\
\text { com Mica }\end{array}$ \\
\hline
\end{tabular}

Unidade Urbano - Unidade caracterizada pela área urbana do município e seus distritos com maior densidade residencial e populacional. É composta pelo perímetro urbano do município (sede municipal) e pelos distritos de Umbu, na porção Centro-Norte do município e o distrito de Saicã localizado na porção Sudoeste de Cacequi totalizando uma área de $6,33 \mathrm{~km}^{2}$ ou $0,27 \%$ de Cacequi. 
Esta unidade está localizada em colinas de arenito eólico $(50,43 \%)$ e também em planícies com litologia de depósitos aluviais atuais $(49,56 \%)$ e possui solos bastante diversificados.

Estas áreas de uso urbano possuem uma disponibilidade de serviços e de infraestrutura maior do que nas outras áreas do município, porém são áreas onde há a maior intervenção antrópica e o maior impacto ambiental.

É uma área do município de ocorrência de impactos ambientais tais como a disponibilidade de resíduos sólidos, esgotos que podem levar a contaminação da drenagem e do lençol freático, como também a concentração da água pluvial através da drenagem pluvial das áreas urbanas e o aumento do escoamento superficial, que podem desencadear a ocorrência de feições erosivas nas áreas de solos mais frágeis.

Unidade Silvicultura - Esta unidade se caracteriza pela cadeia produtiva da silvicultura, com o cultivo de eucalipto voltado para a produção de papel e de carvão vegetal, de modo geral, localizada em grandes propriedades. Representa um total de 3,85\% da área de estudo, localizado em diversas porções do município.

A unidade de silvicultura está presente em sua grande maioria em áreas de colinas, cerca de $95 \%$, e o restante em áreas de planície. Isto se deve pelo fato das áreas de planície serem utilizadas principalmente para o cultivo agrícola, restando assim as áreas menos visadas economicamente, as colinas, para o uso da silvicultura.

Podemos destacar também que a silvicultura se concentra em áreas de litologia de arenito eólico, cerca de 76\%, seguido das áreas de arenito fluvial com grânulos Silicosos (11\%), Arenito Fluvial com Micas (8\%) e Depósitos Aluviais Atuais (5\%).

Estas áreas de silvicultura representam uma nova cadeia econômica do Oeste do Rio Grande do Sul, que vem crescendo desde a década de 1980 como alternativa para o uso de áreas de solo pouco fértil, aumentando os investimentos da área e maior circulação de capital no município, aproveitando áreas de pouco atrativo econômico.

No entanto a silvicultura apresenta alguns impactos ambientais e sociais sobre o município de Cacequi, como no caso da monocultura, a transformação da paisagem nativa do Pampa gaúcho, com a implementação de espécies exóticas, como o Pinus e o Eucalipto e ainda a supressão das espécies nativas por estas mesmas espécies exóticas.

Unidade Planícies do Ibicuí e Cacequi - Presente em 20,5\% do município de Cacequi, esta unidade é característica por ser de áreas de planície de depósitos aluviais atuais, localizadas a 
partir da margem direita do Rio Santa Maria e englobando planícies de outros rios do município na porção Leste e Norte de Cacequi.

Estas planícies possuem seu uso predominante de lavouras, 63,46\% da área da unidade, presente em média em pequenas propriedades rurais do município de Cacequi. Estas lavouras são em sua maioria do cultivo de arroz irrigado, cultura esta que têm tomando bastante espaço nas planícies dos rios da região Oeste do Rio Grande do Sul, devido a facilidade do cultivo nestas áreas. Outro uso que se apresenta em grande quantidade são os campos em $22 \%$ da área da unidade.

O domínio de solos da classe Planossolo e também as características de relevo bastante plano, propiciam a atividade agrícola nesta área do município, o que é importante como área produtiva e utilização econômica desta parcela de terra de Cacequi. Porém este uso agrícola acarreta problemas ambientais, pois há uma grande demanda de água para a lavoura de arroz, e também pela necessidade de proximidade das lavouras de arroz aos canais fluviais há uma supressão da mata ciliar, que representa apenas $10 \%$ da área da unidade. Outro impacto que ocorre nesta unidade é o uso intenso do solo nas margens dos rios que pode acarretar no assoreamento dos mananciais hídricos de Cacequi.

Ainda cabe destacar que estas áreas de planícies próximas aos canais fluviais sofrem com enchentes periódicas causando perda econômica, principalmente nas lavouras de arroz, uma das principais atividades econômicas do município.

Unidade Planícies do Ibicuí, Santa Maria e Saicã - Esta unidade representa 19,1\% da área do município, e se localiza na porção Oeste de Cacequi, nas planícies próximas aos rios Santa Maria, na sua margem esquerda, Itapevi, Saicã e Rio Ibicuí.

Nesta unidade predominam planícies sob a litologia de depósitos aluviais atuais, onde o seu principal uso é o de campos para a pecuária, em cerca de $43,25 \%$ da área, esta atividade é realizada em propriedades que em média são maiores do que no restante do município.

Esta área do município é caracterizada por um relevo de planícies, com declividades inferiores a $2 \%$ e grande disponibilidade de água. Estas características propiciam o cultivo da pecuária extensiva do gado e da ovelha, que está incutida na cultura do povo desta região ajudando na preservação da paisagem natural do pampa gaúcho. No entanto o pisoteio do gado pode levar a degradação do solo nas áreas de solos mais frágeis e também esta atividade secular de pecuária, é uma das responsáveis pela concentração fundiária nesta região.

Também pode-se destacar nesta unidade a significativa presença de mata ciliar, é a porção do município onde as áreas de mata ciliar estão mais preservadas, estando presentes 
em $58,8 \mathrm{~km}^{2}$ o que representa $13,16 \%$ da área da unidade. Isto se deve pelo fato da característica do pecuarista de explorar o ambiente de forma menos intensa do que a agricultura, preservando assim, mais matas e capões.

Unidade Cacequi - A unidade Cacequi é a maior do município, está presente em 34,86\% da área de estudo e está localizada na porção Leste e Centro-Sul do município. Em média esta unidade possui propriedades entre $3,7 \mathrm{~km}^{2}$ e $6,9 \mathrm{~km}^{2}$.

Nesta unidade há um predomínio de litologias de arenito eólico que são pertencentes à Formação Botucatu, uma litologia bastante friável e de fácil desagregação, que junto com as características de relevo de colinas desta unidade, fazem com que nestes locais haja uma presença maior de processos erosivos de voçorocamento, sendo um problema latente desta região do município de Cacequi.

Pode-se destacar como principais usos do solo desta região do município os usos de campos $(46,98 \%)$ e de lavouras $(42,63 \%)$ o que agrava o problema de erosão presente nesta unidade, pois o uso para a agropecuária pode causar problemas de compactação do solo pelo pisoteio do gado, no caso da pecuária, e um período do ano de solo exposto na entressafra, no caso da agricultura.

Pela característica da unidade de solos da classe Argissolos com textura bastante arenosa, a atividade agropecuária deve ser restrita nesta unidade, pela grande suscetibilidade à ocorrência de erosão.

Unidade Nascentes do Saicã - Esta unidade está presente em 7,71\%, ou 180,34km², da área do município e se caracteriza por ser formado de colinas sob a litologia de arenitos fluviais com grânulos silicosos pertencentes a formação Guará. Está presente na porção Sudoeste do município de Cacequi e possui pequena presença de processos erosivos.

Dentro desta unidade, que é caracterizada por médias propriedades, há um predomínio de campos de pecuária, que representam $53,41 \%$ da área, mas também possui significativo uso para lavouras $(41,05 \%)$, seguido do uso de matas ciliares $(4,7 \%)$.

A unidade se caracteriza pela presença de Argissolos Vermelho Alíticos, que são solos pouco férteis, devido à grande presença de alumínio no solo. Por este motivo esta unidade tem predomínio de campos nativos e de pecuária. Deste modo, para o uso de lavouras há a necessidade de grande quantidade de corretivos de solo, podendo contaminar os mananciais hídricos do município. 
Unidade Santa Maria - Esta unidade se localiza na porção central do município, entre os rios Santa Maria e Cacequi. Sua principal característica é do relevo de colinas suaves, com declividades entre 5 e 15\%, sob uma litologia de arenitos eólicos pertencentes a Formação Pirambóia.

O uso do solo nesta unidade é bastante restrito ás lavouras, representando cerca de $67,75 \%$ da área da unidade, isto ocorre devido a baixas declividades facilitando o uso do maquinário agrícola.

Esta área do município não possui muitas restrições quanto ao seu uso, pois está localizada no interflúvio dos rios Cacequi e Santa Maria, com bom acesso a água, relevo de colinas suaves que permitem o uso agropecuário e com pouca ocorrência de processos erosivos. No entanto, os solos desta unidade são geralmente Argissolos Vermelhos Alumínicos, apresentando alto teor de alumínio e baixa fertilidade.

Deste modo esta unidade está suscetível aos impactos da agropecuária, mas principalmente no uso excessivo de corretivos agrícolas no solo para o preparo do terreno para o plantio devido à baixa fertilidade do solo.

Unidade Itapeví - A unidade está localizada espacialmente na porção Central e Oeste do município nos divisores de água entre os rios Saicã e Itapevi, apresentando uma área total de $276,44 \mathrm{Km}^{2}$, que equivale a $11,82 \%$ da área de estudo.

A principal característica desta unidade é a sua litologia fluvial friável, pertencente à Formação Sanga do Cabral segundo Scherer et al (2002). Devido a suas características litológicas e o relevo de colinas suaves, que representam $64,53 \%$ da área da unidade, portanto a Unidade Itapeví é uma área suscetível à ocorrência de processos erosivos lineares.

O principal uso do solo nestas áreas é o campo, com aproximadamente $60 \%$ do total da unidade, que é destinado principalmente para a pecuária de bovinos e ovinos, segundo o censo agropecuário do IBGE de 2006. Também presente em 31,9\% da unidade estão as lavouras, e em menor quantidade se apresentam as matas, em 4,41\% da área.

Esta é uma área onde a ocupação antrópica deve se dar de forma menos intensa devido a sua grande suscetibilidade a ocorrência de processos erosivos, que pode causar perda de solo e consequentemente assoreamento dos rios à jusante da bacia.

Unidade Barão de São Borja - Presente em 192,06 km², ou 8,25\%, da área do município a unidade é caracterizada por Colinas Suaves com predomínio de campos. Está localizada na porção Oeste do município no interflúvio dos rios Santa Maria e Saicã. 
Há um predomínio de solos do tipo Luvissolo Háplico Órtico nesta porção do município, que são solos com pouca profundidade e deficiência hídrica, porém com grande reserva de nutrientes, portanto são solos férteis apesar de pouco espessura. Estes solos apresentam uma mudança textural abrupta, portanto são bastante suscetíveis a processos erosivos lineares.

A litologia presente na unidade é de arenitos fluviais micáceos, que são friáveis e bastante suscetíveis a erosão, apesar das declividades mais baixas, com média de 2 a 5\%. Deste modo o uso do solo deve ser realizado de forma menos intensa de forma a mitigar a erosão nesta unidade.

Unidade Morrotes - Esta unidade é caracterizada por morrotes isolados, formados por erosão diferencial de litótipos mais resistentes. A unidade possui duas feições de morrote, uma na porção Noroeste do município e outra na porção Sudoeste. Representa um total de $0,06 \%$ da área do município.

Nesta porção do município há predomínio de argissolos com grande concentração de alumínio, portanto necessitam de corretivos de solo para a atividade agrícola, ainda é importante considerar que possuem declividades superiores a $15 \%$, limitando o uso de maquinário. Deste modo, o uso do solo predominante nesta área é o de campos nativos, com algum aproveitamento para pastagem do gado.

Devido às grandes declividades nas porções de encostas dos morrotes, associados a litologias mais friáveis, há a ocorrência de processos erosivos lineares nesta unidade, fazendose necessário uma ocupação menos intensa destas áreas.

\section{CONSIDERAÇÕES FINAIS}

De modo geral o município de Cacequi está localizado em uma área de grande fragilidade ambiental, necessitando de um planejamento ambiental contínuo no município, pois os solos são pouco férteis e muito friáveis, tornando grande a ocorrência de erosão linear.

Observa-se uma característica agropecuária bastante forte em Cacequi, com usos voltados a cultivos de arroz nas planícies, e soja, milho e mandioca nas áreas mais elevadas, e ainda a pecuária de gado e de ovelhas. Estes usos devem ser controlados para causarem os menores impactos ambientais possíveis, como erosão, contaminação do solo e dos mananciais hídricos, compactação do solo, assoreamento dos rios, entre outros.

Nos casos de voçorocamento, que ocorre no município em canais de primeira ordem em áreas de surgência na meia encosta, com erosão subterrânea, deve se restringir o uso e 
ocupação no entorno para evitar maiores perdas de solo e preservar as nascentes de rios. Deve-se evitar o uso agrícola nestas áreas de voçorocamento, pois o período do ano em que o solo está exposto, a erosão linear ocorre de forma mais intensa, acelerando a perda de solo e assoreamento dos canais fluviais.

Deste modo, observa-se que as unidades Cacequi e Itapeví são as de maior fragilidade ambiental, em que os usos devem ser mais restritivos, de forma a mitigar os efeitos da erosão.

No entanto, as unidades que apresentam menores restrições quanto ao uso do solo são as das Planícies (Unidade Planícies do Ibicuí, Santa Maria e Saicã e Unidade Planícies do Ibicuí e Cacequi), porém sempre observando o fato de respeitar as Áreas de Preservação Permanente dos rios e também as unidades Nascentes do Saicã e Unidade Santa Maria, pois são menos suscetíveis à erosão e um uso agropecuário é viável nestas áreas.

Portanto, as ferramentas de geoprocessamento se mostram eficientes para os estudos geoambientais, permitindo uma análise ampla e o cruzamento de diversas variáveis. Produzindo então um mapeamento geoambiental que é de grande importância para o ordenamento territorial do município, através do conhecimento das potencialidades e fragilidades de cada porção do território municipal.

\section{REFERÊNCIAS BIBLIOGRÁFICAS}

CHRISTOFOLETTI, A. Geomorfologia. São Paulo: Universidade de São Paulo, 1974.

DE NARDIN, D.; Zoneamento Geoambiental no Oeste do Rio Grande do Sul: Um Estudo em Bacias Hidrográficas. Dissertação de Mestrado, Porto Alegre, 2009.

DINIZ, Noris Costa. Cartografia geotécnica por classificação de unidades de terreno e avaliação de suscetibilidade e aptidão. Revista Brasileira de Geologia de Engenharia e Ambiental. v. 2, n. 1. p. 29 - 77. São Paulo, 2012.

FREITAS FILHO, M. R.; SOUZA, M. J. N.; Análise geoambiental com aplicação de geotecnologias nas nascentes do riacho dos Macacos: bacia do rio Acaraú-CE. Anais XII Simpósio Brasileiro de Sensoriamento Remoto, Goiânia, Brasil, p. 2161-2168; 2005.

OHARA, T.; Zoneamento Geoambiental da Região do Alto-médio Rio Paraíba do Sul e a Carta de Aptidão Física para a Implantação de Obras Viárias. Revista Brasileira de Geociências, Volume 33, 2003.

RADEMANN, L. K., TRENTIN, R., ROBAINA, L. E. S.; Análise das formas de relevo do município de Cacequi - RS. Revista Ciência e Natura, Santa Maria, v.38, n.1, p. 179-188, 2016.

ROBAINA, L. E. S. et al; Método e Técnicas Geográficas Utilizadas na Análise e Zoneamento Ambiental. Revista Geografias, Belo Horizonte, v. 5, p. 36-49, 2009.

SCCOTI, A. A. V.; ROBAINA, L. E. S.; TRENTIN, R. Compartimentação do relevo no município de Manoel Viana-RS. Ciência e Natura, v. 35, p. 64-70, 2013.

SCHERER, C. M. dos S. et al. Arcabouço Estratigráfico do Mesozoico da Bacia do Paraná. In: HOLZ, M.; DE ROS, L. F. O. (Orgs.). Geologia do Rio Grande do Sul. Porto Alegre: Centro de Investigação do Gondwana da Universidade Federal do Rio Grande do Sul, p. 355-374, 2002. 
STRAHLER, A. N. Hypsometric (area-altitude) analysis of erosional topography. Geological Society of America Bulletin, Vol. 63, p. 1117-1142,1952.

TRENTIM, R.; Mapeamento Geomorfológico e Caracterização Geoambiental da Bacia Hidrográfica do Rio Itu - Oeste do Rio Grande do Sul - Brasil. Tese de Doutorado, Curitiba, 2011.

TRENTIN, R; ROBAINA, L. E. S.; Zoneamento Morfolitológico do Município de Manoel Viana-RS. Revista Geografia. V. 22, n 1.p. 2737. Londrina, 2006.

VEDOVELLO, Ricardo. Aplicações da cartografia geoambiental. In: $5^{\circ}$ SIMPÓSIO BRASILEIRO DE CARTOGRAFIA GEOTÉCNICA E GEOAMBIENTAL. São Carlos/SP, 2004.

VILlElA, J. V.; MATtOS, A. Hidrologia Aplicada. São Paulo: McGraw-Hil do Brasil, 1975.

Recebido em 11 de agosto de 2017. Aceito em 28 de outubro de 2017. 